\title{
Prevalence of Irritable Bowel Syndrome: A Community Based Study From Northern India
}

\author{
Govind K Makharia, * Anil K Verma, Ritvik Amarchand, Anil Goswami, Prashant Singh, Abhishek Agnihotri, Faizul Suhail and \\ Anand Krishnan
}

Department of Gastroenterology and Human Nutrition and Centre for Community Medicine, All India Institute of Medical Sciences, New Delhi, India

\section{Background/Aims}

The prevalence of irritable bowel syndrome (IBS) varies from $4 \%$ to $20 \%$ in different Asian nations. Prevalence of IBS in native North Indian community is not known.

\section{Methods}

Between November 2008 to December 2009, we estimated the prevalence of IBS in a rural community of Ballabgarh block, located in Haryana state. A structured questionnaire based on Rome III module was used to collect symptoms related to IBS from all the participants in a door to door survey. A Rome III criterion was used for diagnosis of IBS. IBS was further classified based on predominance of symptoms as constipation predominant, diarrhea predominant, mixed and unspecified based on Rome III module.

\section{Results}

There were 4,767 participants (mean age $34.6 \pm 10.8$, males 50\%). Overall, $555(11.6 \% ; 95 \% \mathrm{Cl}, 10.7-12.5)$ had constipation, 542 (11.4\%; $95 \% \mathrm{Cl}, 10.5-12.3)$ diarrhea and 823 (17.3\%; 95\% Cl, 16.2-18.4) abdominal pain. The overall prevalence of IBS was $4 \%(95 \% \mathrm{Cl}$, 3.5-4.6). The prevalence of constipation predominant IBS was $0.3 \%(95 \% \mathrm{Cl}, 0.16-0.49)$, diarrhea predominant IBS $1.5 \%(95 \% \mathrm{Cl}, 1.18-1.90)$, mixed IBS $1.7 \%(95 \% \mathrm{Cl}, 1.35-2.11)$ and unsubtyped IBS $0.5 \%(95 \% \mathrm{Cl}, 0.32-0.75)$. The prevalence of IBS was significantly higher in females compared with males (4.8\% vs $3.2 \%, P=0.008)$. However, there was no significant difference between males and females in the prevalence of different subtypes of IBS. The prevalence increased with age.

\section{Conclusions}

The prevalence of IBS in a North Indian community is 4\%. IBS poses a significant burden on the rural adults.

\section{(J Neurogastroenterol Motil 2011;17:82-87)}

\section{Key Words}

Asia; Constipation; Diarrhea; Epidemiology; Irritable bowel syndrome

Received: October 8, 2010 Revised: November 18, 2010 Accepted: November 25, 2010

(c) This is an Open Access article distributed under the terms of the Creative Commons Attribution Non-Commercial License (http://creativecommons. org/licenses/by-nc/3.0) which permits unrestricted non-commercial use, distribution, and reproduction in any medium, provided the original work is properly cited.

*Correspondence: Govind K Makharia, MD, DM, DNB, MNAMS

Associate Professor, Department of Gastroenterology and Human Nutrition, All India Institute of Medical Sciences, Ansari nagar, New Delhi-110029, India

Tel: +91-11-26588091, Fax: +91-11-26588091, E-mail: govindmakharia@gmail.com

Financial support: None.

Conflicts of interest: None. 


\section{Introduction}

The magnitude of patients with functional gastrointestinal disorders visiting outpatient clinics is high and accounts for up to one third of outpatient consultations. ${ }^{1}$ Irritable bowel syndrome (IBS) is a functional gastrointestinal disorder characterized by abdominal pain, discomfort and alteration of bowel habits in the absence of any organic disorder. The prevalence of IBS in the general population varies from $9 \%$ to $22 \%$ in the United States and European countries. ${ }^{2-6}$ The rapid socioeconomic development in the last 20 years has also created a transition in the health and environmental situation in Asia. The prevalence of IBS among Asian communities appears to be on the rise. ${ }^{7,8}$

Using Rome II criteria, the prevalence of IBS in Singapore $(8.6 \%)$ and Japan (9.8\%) are comparable to that in Australia (6.9\%) and Europe (9.6\%), although not as high as in Canada and the UK (12\%). ${ }^{9-13}$ The prevalence of IBS both in the community and even in the outpatient clinics varies and depends on the criteria used such as Manning criteria or Rome criteria. ${ }^{5,14}$

Recently, the Indian Society of Gastroenterology conducted a study involving close to 3,000 IBS patients and 4,500 community subjects drawn from 18 centers. ${ }^{15}$ This study was unique in that the authors had adopted an entirely symptoms based diagnosis of IBS rather than using any of the Rome criteria or Manning criteria. The estimated prevalence of IBS in this study was $4.2 \%$. In another study including 2,549 subjects from an urban community from Western part of India (Mumbai), Shah et $\mathrm{al}^{16}$ reported the prevalence of IBS to be around $7.5 \%$ by Manning criteria. Both of the above studies were not really a community based study. While the first study included a mix of patients relatives, hospital staff, students and general population; the second study included relatives of patients visiting hospitals, students and staff members of the hospital. ${ }^{15,16}$ There is a lack of data on the real and native community study from India. We therefore planned to estimate the prevalence of IBS using Rome III criteria in a rural North Indian community.

\section{Materials and Methods}

\section{Study Setting}

The study was conducted in the rural field practice areas of the Centre for Community Medicine, All India Institute of Medical Sciences between October 2008 and December 2009. The rural practice area consisted of 87,002 population spread over 28 villages in Ballabgarh block of Faridabad district and is served by 2 primary health centers and a sub-district level hospital at Ballabgarh. This community is a native stable community and migration rate in this community is minimal negligible.

\section{Sample Size Calculation}

The study was conducted as an add-on on a previous study carried out to elicit the prevalence of celiac disease. A total of 4,767 adults were included in the study and all of them were subjected to questions on IBS. Community studies in India have shown the prevalence of IBS to be approximately $5 \%$ and assuming this to be the expected prevalence, this sample size was expected to give a relative precision of $33 \%$ ie, from $3.4 \%-6.6 \%$ at $5 \%$ alpha error. On using a proportionate to population size sampling list, 12 villages were selected for survey. These included Macchgarh, Sotai, Shahpur Kalan, Jawa, Panehra Kalan, Fatehpur, Chandawali, Chhainsa, Dayalpur, Mauzpur, Atali, Dayalpur and Khera.

\section{Selection of Households and Individuals}

In the chosen villages, alternate households were selected for inclusion in the study. It was decided apriori that from each selected household, 1 adult of either gender (defined as individual aged 18 to 64 years) would be included in the study. To aid selection of the gender of adult to be interviewed from a household, each team was provided with a pre-randomized list. To select 1 adult of the gender out of all adults of the same gender in a household, the names of all adult members of the selected gender in the household were listed. Then 1 member was selected by roll of a dice. The selected individual's consent was taken and an ID number was assigned.

\section{Questionnaire Based on Rome III Criteria}

A simple 10 point objective questionnaire based on Rome III IBS module was used in this study. The English version of the questionnaire was translated into the native language Hindi.

\section{Data Collection}

The field investigators were trained to administer the pre-designed questionnaire. The field investigators were provided with structured survey sheets which they used on listed and enrolled households as they went along with the survey. Any refusals or, locked households were also recorded in the sheet. After self-introduction and informing the purpose of their visit, the field in- 
vestigators sought consent from the respondents for participating in the study.

\section{Quality Control}

During the study, supervisory visits and random checks were done regarding the screening of the subjects. Every 4-6 weeks, review meetings were conducted by study personnel and data were reviewed.

\section{Criteria for the Diagnosis of Irritable Bowel System}

IBS was diagnosed on the basis of Rome III criteria, according to which, recurrent abdominal pain or discomfort at least 3 days per month in the last 3 months with onset of symptoms at least 6 months back was essential for suspecting IBS. In addition, to diagnose a person as IBS, the pain needed to be associated with at least 2 out of 3 features which included improvement of pain or discomfort with defecation and onset of pain or discomfort associated with a change in frequency or form (appearance) of stool.

The patients who were diagnosed as having IBS were further subclassified into diarrhea predominant IBS (IBS-D) if they had loose, mushy or water stools in the last 3 months with no hard or lumpy stools; constipation predominant IBS (IBS-C) if they had hard or lumpy stools with no loose, watery mushy or watery stools in the past 3 months; mixed IBS (IBS-M) if they had both loose and hard stools in the past 3 months; and unsubtyped IBS (IBS$\mathrm{U})$ if they did not report either loose or hard stools in the past 3 months.

\section{Statistical Methods}

All the filled questionnaire sheets were entered in computer using Epi info Version 3.4.1 (CDC's database and statistics software for public health professionals, Atlanta, GA, USA). Double data entry was done for quality control. Entered data were analyzed to assess the characteristics of the study population including age and gender distribution. STATA 9.1 statistical software was used for data analysis. Proportions and 95\% CI were calculated using Chi-square test. A $P$-value less than 0.05 was considered significant.

\section{Results}

In this prospective study to find out the prevalence of IBS in a rural community, 4,767 subjects were interviewed. The mean age of the participants was $34.6 \pm 10.8$ years and 2,383 (50\%) were male. The age distribution is shown in Table 1.

\section{Subjects Having Symptoms of Diarrhea, Con- stipation or Abdominal Pain}

Of 4,767 subjects interviewed, 555 (11.6\%; 95\% CI, 10.712.5) had constipation, $542(11.4 \%$; 95\% CI, 10.5-12.3) had diarrhea and 823 (17.3\%; 95\% CI, 16.2-18.4) had abdominal pain.

\section{Prevalence of Irritable Bowel Syndrome}

One hundred and ninety-one subjects fulfilled the Rome III criteria for diagnosis of IBS. Therefore, the overall prevalence of IBS was $4 \%$ (95\% CI, 3.5-4.6).

\section{Prevalence of Subtypes of Irritable Bowel Syn- drome}

These 191 patients were further subclassified into IBS-D, IBS-C, IBS-M and IBS-U according to the Rome III. The relative proportion of IBS-M was $42.4 \%$, IBS-D $37.7 \%$, IBS-U $13.6 \%$ and IBS-C $6.3 \%$. The prevalence of IBS-C was $0.3 \%$ (95\% CI, 0.16-0.49), IBS-D 1.5\% (95\% CI, 1.18-1.90), IBS-M $1.7 \%$ (95\% CI, 1.35-2.11) and IBS-U 0.5\% (95\% CI, $0.32-$ $0.75)$.

Age and Gender Stratified Prevalence of Irritable Bowel Syndrome and Its Subtypes

The prevalence of IBS increased as the age advanced and was maximum (5.8\%) in the age group 51-60 (Table 1 and Fig. 1).

Table 1. Demographic Details of Irritable Bowel Syndrome Patients

\begin{tabular}{lccc}
\hline \multicolumn{1}{c}{ Parameter } & $\begin{array}{c}\text { Number of } \\
\text { participants } \\
\text { screened }\end{array}$ & $\begin{array}{c}\text { Number of } \\
\text { patients } \\
\text { with IBS }\end{array}$ & $\begin{array}{c}\text { Prevalence of IBS } \\
(95 \% \mathrm{CI})\end{array}$ \\
\hline $\begin{array}{l}\text { Total number } \\
\text { Age stratification }\end{array}$ & 4,767 & 191 & $4.0 \%(3.5-4.6)$ \\
$18-30$ & $1,993(41.8 \%)$ & 63 & $3.2 \%(2.5-4.1)$ \\
$31-40$ & $1,506(31.6 \%)$ & 60 & $4.0 \%(3.1-5.1)$ \\
$41-50$ & $821(17.2 \%)$ & 42 & $5.1 \%(3.7-6.9)$ \\
$51-60$ & $447(9.4 \%)$ & 26 & $5.8 \%(3.8-8.4)$ \\
& & & $P=0.001^{\mathrm{a}}$ \\
Gender & & 77 & $3.2 \%(2.5-4.0)$ \\
Male & 2,383 & 114 & $4.8 \%(4.0-5.7)$ \\
Female & 2,384 & & $P=0.008$ \\
& & & \\
\hline
\end{tabular}

IBS, irritable bowel syndrome.

${ }^{a}$ Chi-square for trend. 
The prevalence of IBS was significantly higher in females compared with males ( $4.8 \%$ vs $3.2 \%, P=0.008)$ (Table 2$)$. However, there was no significant difference between males and females in the prevalence of different subtypes of IBS (Fig. 2). The prevalence of IBS-C, IBS-D, IBS-M and IBS- $U$ in different age groups is shown in Figure 1. The prevalence of IBS- $\mathrm{U}$ in the age group 51-60 was highest among other age groups $(P=0.01)$.

\section{Discussion}

The prevalence of IBS was found to be $4 \%$ in the present Northern Indian rural community with the Rome III criteria. Two other studies on the prevalence of IBS in India were reported. While Shah et $\mathrm{al}^{16}$ reported a prevalence of $7.6 \%$ from Mumbai using Manning criteria; Ghoshal et $\mathrm{al}^{15}$ reported a prevalence of $4.2 \%$ in their prospective multi-center study using clinical criteria. Unlike previous studies, the present study was done in a native Indian rural community which represents $72.2 \%$

Table 2. Gender Distribution and Prevalence of Subtypes of Irritable Bowel Syndrome

\begin{tabular}{lrrr}
\hline & Total & $\begin{array}{c}\text { Men } \\
(\mathrm{n}=2,383)\end{array}$ & $\begin{array}{c}\text { Women } \\
(\mathrm{n}=2,384)\end{array}$ \\
\hline IBS (total) & 191 & $77(3.2 \%)$ & $114(4.8 \%)$ \\
IBS-C (constipation predominant) & 12 & $4(0.2 \%)$ & $8(0.3 \%)$ \\
IBS-D (diarrhea predominant) & 72 & $30(1.3 \%)$ & $42(1.8 \%)$ \\
IBS-M (mixed type) & 81 & $34(1.4 \%)$ & $47(2.0 \%)$ \\
IBS-U (unsubtyped) & 26 & $9(0.4 \%)$ & $17(0.7 \%)$ \\
\hline
\end{tabular}

IBS, irritable bowel syndrome.

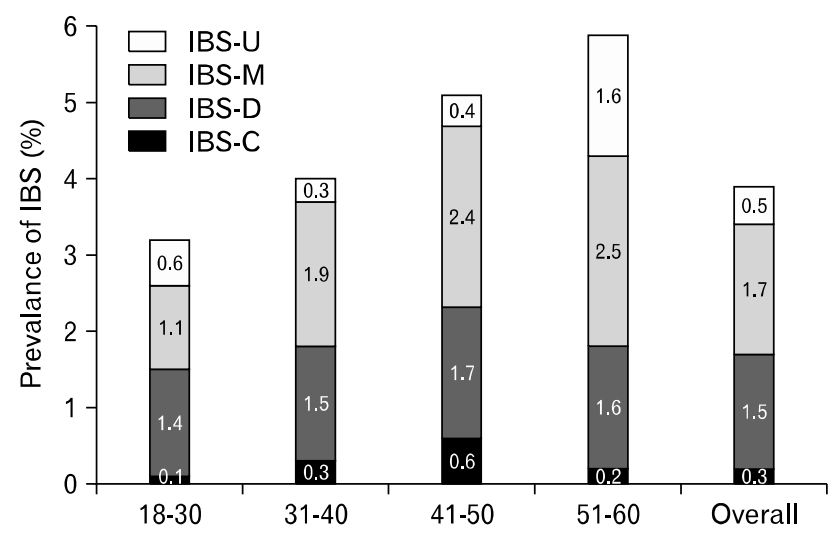

Figure 1. Prevalence of irritable bowel syndrome subtypes in different age group. IBS, irritable bowel syndrome; IBS-C, constipation predominant IBS; IBS-D, diarrhea predominant IBS; IBS-M, mixed IBS; IBS-U, unsubtyped IBS. of Indian population. This study was done as door to door survey using random sampling. The prevalence of IBS in both the above community based study was not only much lower than that reported from the Western countries; but also much lower than community based studies from other Asian countries like Taiwan (22.1\% by Rome II criteria), ${ }^{17}$ China ( $11.5 \%$ by Manning criteria), ${ }^{18}$ Singapore ( $8.6 \%$ by Rome II criteria) ${ }^{9}$ Malaysia $(15.6 \%$ by Rome II criteria), ${ }^{19}$ Bangladesh ( $8.5 \%$ by Rome II criteria), ${ }^{20}$ Pakistan (14\% by Rome II criteria), ${ }^{21}$ Turkey (10.2\% by Rome II criteria), ${ }^{22}$ Korea (6.6\% by Rome II criteria) ${ }^{23}$ and Japan (9.8\% by Rome II criteria). ${ }^{10}$

It is difficult to estimate the true prevalence of IBS as it is known to change depending on the criteria used for diagnosis. ${ }^{11,14,24}$ Revisions of the diagnostic criteria for IBS have led to varying prevalence estimates in the same population. The Rome III criteria is less restrictive and requires a lower symptom frequency than Rome II criteria for IBS. Similarly, the prevalence of IBS has been reported to be higher with Manning criteria and Rome I criteria compared with Rome II criteria. ${ }^{14}$ In a study including 2,000 individuals from Spain, Mearin et $\mathrm{al}^{14}$ reported a much lower prevalence rate using the Rome II criteria (3.3\%) than that obtained using the Manning (10.3\%) and the Rome I criteria $(12.1 \%)$. In another study, where a representative sample of 1,000 adults were assessed for prevalence of IBS using Rome II and Rome III integrative questionnaire; the prevalence for IBS was found to be $2.9 \%$ with Rome II criteria and $11.4 \%$ with Rome III criteria. ${ }^{25}$ Xiong et $\mathrm{al}^{18}$ from Southern part of China reported a prevalence of IBS as $11.5 \%$ with Manning criteria and $5.6 \%$ with Rome II criteria in a population based study including 4,178 subjects. More recently, a good agreement in the prevalence of IBS was reported by Park et $\mathrm{al}^{24}$ from Korea using Rome

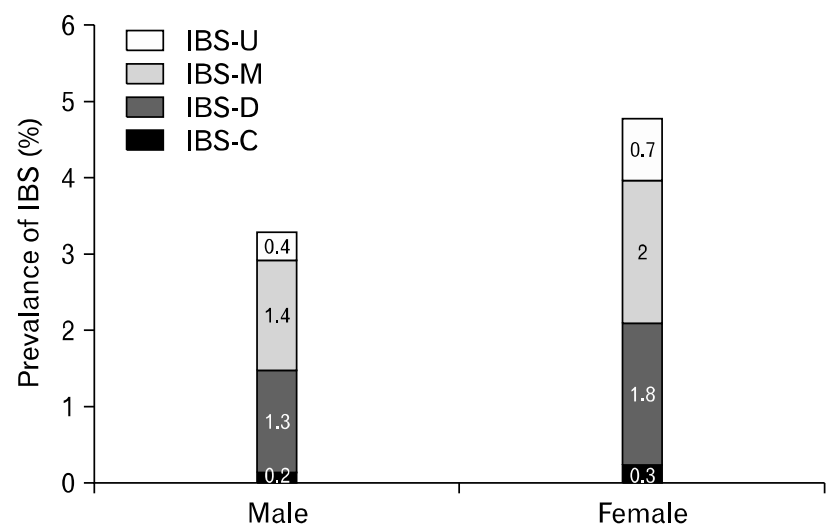

Figure 2. Prevalence of irritable bowel syndrome subtypes in men and women. Abbreviations as Figure 1. 
II (8\%) and Rome III criteria (9\%). There is a criticism that Rome II and Rome III criteria are not suitable for Asian nations because both of them underestimate the prevalence of IBS as aptly shown in the study from Tehran. ${ }^{26,27}$ In a study including 18,180 participants from Tehran Province, Iran, while the prevalence of functional bowel disease was $10.1 \%$, the prevalence of IBS was only $1.1 \%$ using Rome III criteria against the expected higher prevalence rates for IBS. ${ }^{27}$ Our estimation of prevalence of $4 \%$ may be an underestimation of prevalence of IBS.

In this prospective rural community based study, IBS-M with alternating features of diarrhea and constipation was the most common form of IBS in India with prevalence of $1.7 \%$ closely followed by IBS-D with prevalence of $1.5 \%$. Predominance of IBS-M among IBS patients has also been reported from the United State. ${ }^{3}$ In the present study, the prevalence of constipation predominant IBS was $0.3 \%$ and this may be due to a higher fiber intake and faster gut transit time among Indians. ${ }^{28}$

The prevalence of IBS in the present study was higher in females compared to males. While IBS is more common in women than men in many Western countries; no consistent differences however has been observed from Asia. ${ }^{2,3,12}$ While studies from many Asian nations such as Hong Kong, Taiwan and Singapore have not revealed a gender difference in the prevalence of IBS, a female predominance has been reported from Bangladesh, Vietnam, Malaysia and Japan. ${ }^{17,19,20,29-34}$ In the 2 previous hospital based studies from India, IBS was reported to be more common in males. ${ }^{15,16}$ On the other hand, the prevalence of IBS between female and male was almost same in those who had symptoms of IBS in the community study from India with non health seekers. ${ }^{15}$ Since India is a male dominant society, health seeking behaviour of males is probably the best explanation for difference in the prevalence of IBS in the studies conducted in hospital setting and those done in the community. ${ }^{13,35-38}$

Female sex hormones affecting gastrointestinal motility and differences in the serotonin synthesis in brain are proposed mechanisms for higher occurrence of motility disorders in women. ${ }^{39,40}$

Considering the current prevalence of IBS in our community, IBS still remains an under-diagnosed gastrointestinal disorder. This could be either due to low health seeking behavior of the community or, due to poor ability of medical fraternity in primary health care to diagnose the condition. There is no study available which correlates the severity of illness with health care seeking pattern of these patients. Further studies are therefore needed to study the health care seeking pattern of IBS patients in our population and to assess the severity of IBS. Also, there is no popula- tion based investigation on the impact of IBS on the health-related quality of life (HRQOL) in India. Assessment of HRQOL in these patients will not only give an insight on severity of disease but also help in optimizing the treatment of IBS.

The strength of this study is that it is a community based study with large sample size. This study is limited to native rural population and has not included urban population. There may be a difference in the prevalence of IBS amongst rural and urban population.

In conclusion, the prevalence of IBS in a Northern Indian community is $4 \%$. The predominant subtype of IBS in this community is IBS-M.

\section{Acknowledgements}

We acknowledge and recognize the help of Dr. Rajeew $\mathrm{P}$ Tiwari for supervising collection of data; all the field investigators namely Abhishek, Prem Prakash, Vinod Kumari and Kavita Dangwal for collection of data of participants and Ms. Namita Rawat for data entry.

\section{References}

1. Okumura T, Tanno S, Ohhira M, Tanno S. Prevalence of functional dyspepsia in an outpatient clinic with primary care physicians in Japan. J Gastroenterol 2010;45:187-194.

2. Jones R, Lydeard S. Irritable bowel syndrome in the general population. BMJ 1992;304:87-90.

3. Hungin AP, Chang L, Locke GR, Dennis EH, Barghout V. Irritable bowel syndrome in the United States: prevalence, symptom patterns and impact. Aliment Pharmacol Ther 2005;21:1365-1375.

4. Minocha A, Johnson WD, Abell TL, Wigington WC. Prevalence, sociodemography, and quality of life of older versus younger patients with irritable bowel syndrome: a population-based study. Dig Dis Sci 2006;51:446-453.

5. Talley NJ. Functional gastrointestinal disorders as a public health problem. Neurogastroenterol Motil 2008;20(suppl 1):121-129.

6. Locke GR 3rd. The epidemiology of functional gastrointestinal disorders in North American. Gastroenterol Clin North Am 1996;25: $1-19$.

7. Gwee KA, Bak YT, Ghoshal UC, et al. Asian consensus on irritable bowel syndrome. J Gastroenterol Hepatol 2010;25:1189-1205.

8. Gwee KA, Lu CL, Ghoshal UC. Epidemiology of irritable bowel syndrome in Asia: something old, something new, something borrowed. J Gastroenterol Hepatol 2009;24:1601-1607.

9. Gwee KA, Wee S, Wong ML, Png DJ. The prevalence, symptom characteristics, and impact of irritable bowel syndrome in an Asian urban community. Am J Gastroenterol 2004;99:924-931.

10. Miwa H. Prevalence of irritable bowel syndrome in Japan: internet survey using Rome III criteria. Patient Prefer Adherence 2008;2: 
143-147.

11. Boyce PM, Koloski NA, Talley NJ. Irritable bowel syndrome according to varying diagnostic criteria: are the new Rome II criteria unnecessarily restrictive for research and practice? Am J Gastroenterol 2000;95:3176-3183.

12. Hungin AP, Whorwell PJ, Tack J, Mearin F. The prevalence, patterns and impact of irritable bowel syndrome: an international survey of 40,000 subjects. Aliment Pharmacol Ther 2003;17:643-650.

13. Thompson WG. Irritable bowel syndrome: pathogenesis and management. Lancet 1993;341:1569-1572.

14. Mearin F, Badía X, Balboa A, et al. Irritable bowel syndrome prevalence varies enormously depending on the employed diagnostic criteria: comparison of Rome II versus previous criteria in a general population. Scand J Gastroenterol 2001;36:1155-1161.

15. Ghoshal UC, Abraham P, Bhatt C, et al. Epidemiological and clinical profile of irritable bowel syndrome in India: report of the Indian Society of Gastroenterology Task Force. Indian J Gastroenterol 2008; 27:22-28.

16. Shah SS, Bhatia SJ, Mistry FP. Epidemiology of dyspepsia in the general population in Mumbai. Indian J Gastroenterol 2001;20:103106.

17. Lu CL, Chen CY, Lang HC, et al. Current patterns of irritable bowel syndrome in Taiwan: the Rome II questionnaire on a Chinese population. Aliment Pharmacol Ther 2003;18:1159-1169.

18. Xiong LS, Chen MH, Chen HX, Xu AG, Wang WA, Hu PJ. A population-based epidemiologic study of irritable bowel syndrome in South China: stratified randomized study by cluster sampling. Aliment Pharmacol Ther 2004;19:1217-1224.

19. Rajendra S, Alahuddin S. Prevalence of irritable bowel syndrome in a multi-ethnic Asian population. Aliment Pharmacol Ther 2004;19: 704-706.

20. Masud MA, Hasan M, Khan AK. Irritable bowel syndrome in a rural community in Bangladesh: prevalence, symptoms pattern, and health care seeking behavior. Am J Gastroenterol 2001;96:15471552.

21. Jafri W, Yakoob J, Jafri N, Islam M, Ali QM. Irritable bowel syndrome and health seeking behaviour in different communities of Pakistan. J Pak Med Assoc 2007;57:285-287.

22. Yilmaz S, Dursun M, Ertem M, Canoruc F, Turhanoğlu A. The epidemiological aspects of irritable bowel syndrome in Southeastern Anatolia: a stratified randomised community-based study. Int J Clin Pract 2005;59:361-369.

23. Han SH, Lee OY, Bae SC, et al. Prevalence of irritable bowel syndrome in Korea: population-based survey using the Rome II criteria. J Gastroenterol Hepatol 2006;21:1687-1692.

24. Park DW, Lee OY, Shim SG, et al. The differences in prevalence and sociodemographic characteristics of irritable bowel syndrome According to Rome II and Rome III. J Neurogastroenterol Motil 2010; 16:186-193.

25. Sperber AD, Shvartzman P, Friger M, Fich A. A comparative reappraisal of the Rome II and Rome III diagnostic criteria: are we get- ting closer to the 'true' prevalence of irritable bowel syndrome? Eur J Gastroenterol Hepatol 2007;19:441-447.

26. Gwee KA, Ghoshal UC. The Rome criteria divides, distorts and dilutes the prevalence of irritable bowel syndrome. Saudi J Gastroenterol 2010;16:143-144.

27. Khoshkrood-Mansoori B, Pourhoseingholi MA, Safaee A, et al. Irritable bowel syndrome: a population based study. J Gastrointestin Liver Dis 2009;18:413-418.

28. Singh N, Makharia GK, Joshi YK. Dietary survey and total dietary fiber intake in patients with irritable bowel syndrome attending a tertiary referral hospital. Indian J Gastroenterol 2008;27:66-70.

29. Cheung TK, Lam KF, Hu WH, et al. Positive association between gastro-oesophageal reflux disease and irritable bowel syndrome in a Chinese population. Aliment Pharmacol Ther 2007;25:1099-1104.

30. Ho KY, Kang JY, Seow A. Prevalence of gastrointestinal symptoms in a multiracial Asian population, with particular reference to refluxtype symptoms. Am J Gastroenterol 1998;93:1816-1822.

31. Zuckerman MJ, Nguyen G, Ho H, Nguyen L, Gregory GG. A survey of irritable bowel syndrome in Vietnam using the Rome criteria. Dig Dis Sci 2006; 5 1:946-951.

32. Tan YM, Goh KL, Muhidayah R, Ooi CL, Salem O. Prevalence of irritable bowel syndrome in young adult Malaysians: a survey among medical students. J Gastroenterol Hepatol 2003;18:14121416.

33. Shiotani A, Miyanishi T, Takahashi T. Sex differences in irritable bowel syndrome in Japanese university students. J Gastroenterol 2006;41:562-568.

34. Kumano H, Kaiya H, Yoshiuchi K, Yamanaka G, Sasaki T, Kuboki T. Comorbidity of irritable bowel syndrome, panic disorder, and agoraphobia in a Japanese representative sample. Am J Gastroenterol 2004;99:370-376.

35. Gupta D, Ghoshal UC, Misra A, Misra A, Choudhuri G, Singh K. Lactose intolerance in patients with irritable bowel syndrome from northern India: a case-control study. J Gastroenterol Hepatol 2007; 22:2261-2265.

36. Banerjee R, Choung OW, Gupta R, et al. Rome I criteria are more sensitive than Rome II for diagnosis of irritable bowel syndrome in Indian patients. Indian J Gastroenterol 2005;24:164-166.

37. Malhotra S, Rana SV, Sinha SK, Khurana S. Dietary fiber assessment of patients with irritable bowel syndrome from Northern India. Indian J Gastroenterol 2004;23:217-218.

38. Kapoor KK, Nigam P, Rastogi CK, Kumar A, Gupta AK. Clinical profile of irritable bowel syndrome. Indian J Gastroenterol 1985;4: $15-16$.

39. Nishizawa S, Benkelfat C, Young SN, et al. Differences between males and females in rates of serotonin synthesis in human brain. Proc Natl Acad Sci USA 1997;94:5308-5313.

40. Wald A, Van Thiel DH, Hoechstetter L, et al. Gastrointestinal transit: the effect of the menstrual cycle. Gastroenterology 1981;80:14971500 . 